\title{
Transdisciplinarity for Sustainability: A Unifying Framework for Navigating Transformational Learning Systems
}

\section{Dr. Linda Vanasupa, California Polytechnic State University, San Luis Obispo}

Linda Vanasupa has been a professor of materials engineering at the California Polytechnic State University since 1991. She also serves as co-director of the Center for Sustainability in Engineering at Cal Poly. Her life's work is focused on creating ways of learning, living and being that are alternatives to the industrial era solutions-alternatives that nourish ourselves, one another and the places in which we live. Her Ph.D. and M.S. degrees are in materials science and engineering from Stanford University and her B.S. degree in metallurgical engineering from the Michigan Technological University.

\section{Dr. Carol J. Thurman, Georgia Institute of Technology}

Dr. Carol Thurman serves as the Academic Assessment Manager for Georgia Tech's Center for ServeLearn-Sustain. She holds a doctorate in Educational Policy Studies with a concentration in Research, Measurement, and Statistics. Dr. Thurman's professional experience includes higher education academic and program assessment, program evaluation, project management, teaching K-12 both in the U.S. and internationally, teaching university research and statistics courses, and serving as a K-12 school district research specialist. Dr. Thurman's research interests include transdisciplinary research approaches to understanding and addressing sustainability social issues that reside in the complex space. 


\title{
Transdisciplinarity for sustainability: A unifying framework for navigating transformational learning systems
}

\begin{abstract}
We began this work with an intent to create an assessment strategy for community-engaged learning focused on sustainability. Through reviewing existing approaches, we discovered that the salient learning modality for such a purpose - transdisciplinarity - differs profoundly from traditional engineering education settings. Further, this form of community-engaged learning offers an authentic setting to develop many of the integrated student outcomes stated in the new engineering accreditation criteria. We contend that effective transdisciplinary learning is a means to the oft-stated goal of systemic transformation in engineering education, particularly for sustainability aims. However, this complex, dynamic systems view of engineering education represents a radical departure from education-as-usual and thus requires a similarly radical departure from research- and assessment- -as-usual. It reflects a shift in the unit of analysis: from a singular focus on student learning outcomes to a broader view that captures learning at the transdisciplinary system level. It also requires a shift from assessing/judging student learning based on learning outcomes alone to that of navigating the learning process. This paper opens a dialogue on a compelling question for engineering education: How do we design and navigate dynamic systems of learning that themselves create sustainable communities? We suggest an approach that includes monitoring system-level properties rather than a singular focus on the learning at the individual level. A review of literature reveals nascent alignment amongst researchers on core sustainability competencies needed for student learning, however, there is no consensus on systems-level learning approaches. Based on a literature review and lived experiences, we offer a unifying framework through a systems-level lens for essential properties of assessing community-engaged learning for sustainability: holistic, participatory and adaptive. We also offer reflections on qualities of transdisciplinary research approaches that are coherent with complex dynamic systems and suggest future directions.
\end{abstract}

\section{Introduction}

Engineers are expected to play a critical role in addressing sustainability as well as other complex societal global challenges. Transdisciplinarity is a mode of community-engaged learning that is increasingly recognized as an essential means to address such complex societal challenges [1]. In contrast to traditional engineering classrooms, a transdisciplinary setting involves novice, lay and experts jointly addressing issues of shared concern [2], [3], [4]. Furthermore, a transdisciplinary approach recognizes that solutions will require bringing together research teams of experts from the natural and social science disciplines working together with laypersons who have the lived experience at the community-level. This mode of communityengaged discovery is particularly salient for addressing sustainability issues because of its emphasis on involving people who are affected and integrating their perspectives in joint decision-making [5].

In many ways, this type of community-engaged learning around sustainability, described below, provides a direct opportunity to practice all seven of the new Accreditation Board on Engineering and Technology (ABET) student outcomes, Table 1. Although we are advocating a 
shift from a sole focus on student outcomes, we call attention to outcomes 4 and 5, which reflect system-level abilities, "An ability to recognize ethical and professional responsibilities in engineering situations and make informed judgments, which must consider the impact of engineering solutions in global, economic, environmental, and societal contexts; An ability to function effectively on a team whose members together provide leadership, create a collaborative and inclusive environment, establish goals, plan tasks, and meet objectives." Transdisciplinary learning mirrors an authentic setting of "real world" engineering practice.

Table 1. New Accreditation Board on Engineering and Technology (ABET) student outcomes.

\begin{tabular}{ll}
\hline $\mathbf{1}$ & $\begin{array}{l}\text { An ability to identify, formulate, and solve complex engineering problems by applying principles of } \\
\text { engineering, science, and mathematics; }\end{array}$ \\
$\mathbf{2}$ & $\begin{array}{l}\text { An ability to apply engineering design to produce solutions that meet specified needs with consideration of } \\
\text { public health, safety, and welfare, as well as global, cultural, social, environmental, and economic factors; }\end{array}$ \\
$\mathbf{3}$ & $\begin{array}{l}\text { An ability to communicate effectively with a range of audiences; } \\
\text { An ability to recognize ethical and professional responsibilities in engineering situations and make informed } \\
\text { judgments, which must consider the impact of engineering solutions in global, economic, environmental, and } \\
\text { societal contexts }\end{array}$ \\
$\mathbf{4}$ & $\begin{array}{l}\text { An ability to function effectively on a team whose members together provide leadership, create a } \\
\text { collaborative and inclusive environment, establish goals, plan tasks, and meet objectives }\end{array}$ \\
$\mathbf{6}$ & $\begin{array}{l}\text { An ability to develop and conduct appropriate experimentation, analyze and interpret data, and use } \\
\text { engineering judgment to draw conclusions }\end{array}$ \\
$\mathbf{7}$ & An ability to acquire and apply new knowledge as needed, using appropriate learning strategies. \\
\hline
\end{tabular}

At the same time, transdisciplinarity profoundly differs from traditional engineering education (as described below); Assessing learning in this type of community engagement must differ in equally profound ways from traditional assessment. Very importantly, transdisciplinarity is itself a system of learning. ${ }^{1}$ The systems' parts, or part-icipants, are many: lay person, novice, and expert. The desired learning outcomes are properties that emerge from the learning system as a whole, rather than an ability that can be found in the systems' parts. Analogously, one could not assess a synchronized swimming team's ability to perform an elaborately choreographed routine by assessing individual swimmers' ability to swim laps.; the ability to swim is a necessary but insufficient individual skill. The choreographed team performance is a collective behavior that manifests only at the system level. Similarly, the collective nature of ABET student outcome 5 is underscored by the phrase,

“...whose members together [emphasis added]...provide...create...establish...plan and meet...".

We propose that along with this vision of systems-level outcomes, there needs to be a shift to designing and enacting systems-level learning. It is a shift away from a sole focus on student learning outcomes characteristic of traditional educational design and assessment approaches, with a recognition that transdisciplinary systems are learning "organisms"; learning necessarily takes place at multiple levels: participant level (student, lay, expert), institutional level, community level, and societal level. As a result, systems-level learning essentially transforms systems in the process. In other words, effective transdisciplinary learning is a means to the oftstated goal of systemic transformation in engineering education.

\footnotetext{
${ }^{1}$ We use the term "learning" as an umbrella for all types of learning: research, discovery, and education.
} 
How do we effectively design and engage in such learning systems? This paper opens the dialogue on working at the systems-level of learning. Our educational aspiration is one of sustainability, broadly defined. We focus on transdisciplinarity as a salient learning modality for reasons explained below. We then describe our methods. This is followed by a summary of past and emergent approaches to assessing sustainability learning. We then offer a unifying framework for navigating transdisciplinary learning in the context of sustainability. We finish by reflecting on changes in research approaches that would be needed to learn in such complex dynamic systems.

\section{Note on language: Evaluation/Assessment/Monitoring/Navigation}

Throughout this paper, we are concerned about actions during the implementation phase of sustainability learning initiatives. Our preferred term for this activity is "navigation." In our model, navigation would include a suite of activities, such as monitoring indicators and making adjustments. Evaluation and assessment are included in the wider scope of navigation.

Transdisciplinarity: A salient learning modality for community-engaged learning for sustainability

While transdisciplinary can appear similar in form to multidisciplinary or interdisciplinary efforts, it differs significantly in its substance, aims, assumptions about reality and outcomes as shown in Table 2. Transdisciplinarity is differentiated from other forms of interdisciplinarity by "transcending, transgressing, transforming" characteristics [3]. From the National Academies of Sciences, [1,p. 20] "Multidisciplinary research is typically understood as the sequential or additive combination of ideas or methods drawn from two or more disciplines or fields to address the focal problem. Interdisciplinary research involves the integration of perspectives, concepts, theories, and methods from two or more disciplines or fields to address the problem. Transdisciplinary research entails not only the integration of discipline-specific approaches, but also the extension of these approaches to generate fundamentally new conceptual frameworks, hypotheses, theories, models, and methodological applications that transcend their disciplinary origins."

Transdisciplinary research requires interaction and boundary-crossing collaborative discovery [6], [7], [8], [9]. It has been used as a community-engaged learning modality for sustainability [10], [11], [12]. Unlike the controlled laboratory settings typical of science and engineering, transdisciplinary settings are complex, dynamic social systems with open boundaries, non-linear behavior, self-organization, and recursive interactions among agents that hold widely different values. In short, transdisciplinarity is a dynamically complex system. Those who have used this learning modality report emergent results, often unpredicted [13], [14] and transformational at the participant and systems level [15], [16]. We therefore consider transdisciplinary learning modalities as both model and means to systemic educational changes for sustainability.

For example, consider a project on water capture and storage for a small community. Although appearing simple, this example is a sustainability issue, which represents a complex system. Such systems are characterized by non-linear behavior, and cut across economic, environmental, and social domains [16]. An approach to addressing the challenge of water capture could be to 
engage an interdisciplinary student team of civil engineers and environmental engineers to design such a system. The process might include gathering water use data from the community and presenting prototypes. Alternatively, this project could be approached as a transdisciplinary endeavor. This would involve drawing on the lived experience of the stakeholders: the affected community members, government representatives, learners and experts from various disciplines sociology, engineering, philosophy, environmental science, biology, communication studies, business, political science, kinesiology, nutrition and food science. They would begin by reflecting on the community's relationship with water: Where does it come from? How is it used? Who benefits? Who pays? How is water not serving the community? What are the social/political impacts of water availability? Addressing these questions necessarily involves "systemic integration, transsector interaction," high degrees of shared decision-making, and collaborative restructuring amongst lay and expert participants [3].

Table 2. Modes of research, their forms and substance (adapted from Klein [3]).

\begin{tabular}{|c|c|c|}
\hline & Multi-/Inter- disciplinarity & Transdisciplinarity \\
\hline Participants & $\begin{array}{l}\text { Experts, Novices; shared beliefs about } \\
\text { what counts as knowledge and how to } \\
\text { obtain it }\end{array}$ & $\begin{array}{l}\text { Experts, Laymen, Novices; wide diversity } \\
\text { of perspectives and beliefs about valid } \\
\text { knowledge and its sources }\end{array}$ \\
\hline Defining characteristics & $\begin{array}{l}\text { Coordinating, linking, and blending } \\
\text { expert knowledge }\end{array}$ & $\begin{array}{l}\text { Transcending known solutions, } \\
\text { transgressing disciplinary and institutional } \\
\text { boundaries }\end{array}$ \\
\hline Aims & Design/Research Goals & Scientific and Societal Benefits \\
\hline Interactions & $\begin{array}{l}\text { Cooperative, expert-centric power and } \\
\text { decisions }\end{array}$ & $\begin{array}{l}\text { Collaborative, shared power and joint } \\
\text { decision-making }\end{array}$ \\
\hline $\begin{array}{l}\text { Integration of various } \\
\text { perspectives }\end{array}$ & Partial, complementing, supplementary & $\begin{array}{l}\text { Systemic, hybridizing, transsector, } \\
\text { unifying }\end{array}$ \\
\hline Outcomes & $\begin{array}{l}\text { Incremental, novel extension of existing } \\
\text { solutions; bridge building }\end{array}$ & $\begin{array}{l}\text { Transformational, systemic disruption and } \\
\text { restructuring }\end{array}$ \\
\hline $\begin{array}{l}\text { Assumptions about the nature } \\
\text { of reality }\end{array}$ & Discipline-derived and unquestioned & Complex/plural and recursively examined \\
\hline
\end{tabular}

Some excellent case studies and heuristics have been developed for designing and implementing sustainability projects in this learning modality. For example, the reader is directed to the report by Brundiers et al. [16]. But in general, there is a paucity of information to enable the effective learning and navigation at the systems-level: How do we assure that the project has both the form and substance of transdisciplinarity? What conditions need to be in place in order to foster emergent results aligned with overarching aims? How do we measure learning at multiple levels of the system? What, if anything, can assure the achievement of goals?

Amid these many unanswered questions, we open the dialogue on how to measure learning at the systems level. In the following section, we offer a summary of past approaches. We follow with a proposal for a unifying framework that offers a cohesive look at the essential properties of the system of learning.

Methods

The views presented in this paper were derived through a synthesis of literature review and lived experiences. The authors used Google Scholar, ProQuest, and ERIC databases to search for key terms, "sustainability," "assessment," "community," "transdisciplinary," "competencies," 
"complexity." The initial intent was to create a view of existing and emergent models of assessing learning for sustainable design in engineering education. We filtered the articles for relevancy by reading the abstracts of the articles. We used the same search terms in the ASEE proceedings database and sorted through the results to look for articles that met a relevance factor of 1.0 or above. After reading these search result articles, the authors also participated in a webinar on emerging sustainability competencies presented by Peter Buckland and Elly Engle [17] of the Sustainability Curriculum Consortium. ${ }^{2}$ The analysis yielded a multiplicity of approaches, each situationally-appropriate. Through a dialectic process around the readings and integration of perspectives from past lived experience, the authors formulated a unifying framework. This framework is meant to address the question, "Is the substance of a learning system for sustainable design coherent with the conditions required to favor the emergence of systemic, transformational learning?"

Past, Present, and Emergent Practices in Assessing Sustainability Learning

Traditionally, assessing learning that seeks to foster the creation of sustainable communities has taken two major forms: Legacy approaches that reflect the assumptions of simple cause-effect relationships and are rooted at the individual level, and emergent approaches that have a wideangle or systemic lens and are coherent with dynamically complex systems. We discuss each below in Legacy models, and Emergent models.

\section{Legacy models}

What we are calling "legacy models" are approaches consistent with the following simple system assumptions:

- What is observed is independent of and unaffected by the observation/measurement;

- Cause and effect are direct and knowable;

- The whole is a sum of what is found in the parts.

With some notable exceptions ${ }^{3}$, these legacy models focus on assessing student knowledge, skills and attitudes. This can take many forms, such as direct assessments of specific learning objectives, but the essential commonalities are: 1) Listings of skills, knowledge and attitudes considered essential to sustainability; 2) students' abilities are the primary subject of study by which the learning system is assessed.

Watson \& Barrella [18] published a systematic review of the literature in ASEE publications on assessing sustainability learning which provides a comprehensive look at what we are calling first generation legacy approaches. The vast majority of these first generation approaches are designed to assess students' conceptual knowledge of and interest in sustainability, skills obtained for project design, or attitudes, beliefs, and interests regarding sustainability. The approaches vary. For example, Watson et al. [19] use a rubric-based approach to assess a direct measure of students' developmental stage with respect to the level of integration of sustainability

\footnotetext{
${ }^{2}$ For information on the Sustainability Curriculum Consortium, see http://curriculumforsustainability.org.

${ }^{3}$ For example, Pawley et al. [20] offer a comparative analysis of sustainability principles in existing courses.
} 
conceptual understanding. Others use surveys that ask students to rate their understanding or identify their agreement with ideas. With one exception, there is no mention of learning at other levels of the system in the nearly 30 approaches of the Watson \& Barrella [18] study. For example, other participants' development (e.g., faculty, community partners) are not assessed nor are any proxy indicators of the learning system. Those who have looked at sustainable education more broadly also focus on concepts as student learning outcomes [21], [22].

We found four legacy approaches that we call second generation. These second generation models maintain focus on student learning outcomes but shift from discrete skills, knowledge, and attitudes to students' core competencies that integrate across these domains. These core competencies address calls for a broad set of skills to meet sustainability challenges in creative and holistic ways [21], [16], [23]. They fall within a higher level of development in common educational taxonomies such as Bloom's taxonomy [24], Perry's theory of intellectual and ethical development [25], and Kitchener's Reflective Judgement [26]. No consensus has been reached, however, as to what those core competencies should be [27], with different researchers identifying different competencies [28], [27], [23]. There is some commonality across models as shown in Table 2, below, which we have synthesized from our four salient sources: (E) Engels et al. [29], (VE) Van Epps et al. [27], (W) Wiek et al. [23], and (B) Brundiers et al. [16].

Table 3. Commonality in core competencies in learning for sustainable communities. Sources: (E) Engels et al. [29], (VE) Van Epps et al. [27], (W) Wiek et al. [23], and (B) Brundiers et al. [16].

\begin{tabular}{|c|c|}
\hline Theme & Examples within the theme \\
\hline \multirow[t]{4}{*}{ Creativity } & $\begin{array}{l}\text { Envision, develop and apply innovative and strategic scenarios, frameworks, questions, and solutions } \\
\text { in order to adapt to changing and challenging situations. (Creativity/Imagination) [E] }\end{array}$ \\
\hline & Upfront problem framing before solutions are explored (Design Thinking) [VE] \\
\hline & $\begin{array}{l}\text { See a need, conceptualize the scope of the work to be done to address the project, determine a list of } \\
\text { tasks and appropriate timeline for completing those task [VE] }\end{array}$ \\
\hline & $\begin{array}{l}\text { Integrate knowledge across domains, take risks, and embrace contradictions (Innovation \& Creativity) } \\
\text { [VE] }\end{array}$ \\
\hline \multirow[t]{3}{*}{ Ethics } & $\begin{array}{l}\text { The ability to identify, assess, apply and reconcile values and goals in the context of sustainability } \\
\text { (Ethical Literacy) [E] }\end{array}$ \\
\hline & $\begin{array}{l}\text { Assess their own ethical values and the social context of problems; recognize ethical issues in a variety } \\
\text { of settings; think about how different ethical perspectives might be applied to ethical dilemmas and } \\
\text { consider the ramifications of alternative actions (Ethical Reasoning) [VE] }\end{array}$ \\
\hline & Assess a problem and its context comprehensively with respect to sustainability (Normative) [W] \\
\hline \multirow[t]{5}{*}{$\begin{array}{l}\text { Interpersonal } \\
\text { dynamics }\end{array}$} & $\begin{array}{l}\text { Work in teams and in different knowledge communities; engage with stakeholders establishing } \\
\text { consistent vocabularies and facilitating participatory research and decision making in collaboration } \\
\text { with experts from academia, industry, government, and civil society (Collaborative) [B] }\end{array}$ \\
\hline & $\begin{array}{l}\text { Capacity for comprehending, motivating, supporting, relating to, and communicating across a diverse } \\
\text { range of individuals, networks, political systems and other organizations (Interpersonal Literacy) [E] }\end{array}$ \\
\hline & $\begin{array}{l}\text { Minimizing potential misunderstanding and overcoming any barriers to communication at each stage } \\
\text { in the communication process (Effective Communication) [VE] }\end{array}$ \\
\hline & $\begin{array}{l}\text { Engage meaningfully with others and participate as part of a team (Social Interaction \& Teamwork) } \\
\text { [VE] }\end{array}$ \\
\hline & $\begin{array}{l}\text { Collaboration with researchers from other disciplines, and stakeholders in government businesses and } \\
\text { civil society [W] }\end{array}$ \\
\hline
\end{tabular}




\begin{tabular}{|c|c|}
\hline \multirow[t]{4}{*}{ Systems Thinking } & $\begin{array}{l}\text { Capacity to comprehend and analyze complex systems across different domains and at multiple scales } \\
\text { [E] }\end{array}$ \\
\hline & $\begin{array}{l}\text { Envision, describe, and analyze systems as a dynamic entity of interconnected parts acting as a whole, } \\
\text { situated within an environment, that are seeking equilibrium [VE] }\end{array}$ \\
\hline & Analyze a sustainability problem from a holistic perspective [W] \\
\hline & Assess a problem and its context comprehensively with respect to sustainability (Normative) [W] \\
\hline \multirow[t]{5}{*}{ Temporal Action } & $\begin{array}{l}\text { Integrates systemic, anticipatory, normative, and action-oriented competencies; Analyze and } \\
\text { understand the status-quo (current state) and past developments (history); creating future scenarios and } \\
\text { sustainability visions, assessing current, past, and future states against value-laden principles of } \\
\text { sustainability; and develop strategies to move from the current state towards a sustainable future } \\
\text { (Strategic thinking) [B] }\end{array}$ \\
\hline & $\begin{array}{l}\text { Understand and draw upon past states and narratives and to anticipate future societies, environments } \\
\text { and situations (Temporal thinking) [E] }\end{array}$ \\
\hline & $\begin{array}{l}\text { Create intervention strategies to avoid undesirable scenarios and realize sustainability visions } \\
\text { (Strategic) [W] }\end{array}$ \\
\hline & $\begin{array}{l}\text { Construct non-intervention scenarios about how the problem might play out in the future } \\
\text { (Anticipatory) }[\mathrm{W}]\end{array}$ \\
\hline & Envision sustainable future states in contrast to the non-intervention scenarios (Normative) [W] \\
\hline \multirow[t]{2}{*}{$\begin{array}{l}\text { Grounded } \\
\text { Knowledge }\end{array}$} & $\begin{array}{l}\text { Often not explicitly stated. Can include disciplinary mastery and/or knowledge derived from other } \\
\text { grounds of lived experiences (e.g., lay knowledge). }\end{array}$ \\
\hline & Practical knowledge [B], Disciplinary knowledge [VE], Execute [VE] \\
\hline
\end{tabular}

The approach of Brundiers et al. [16] represents a step toward emergent models. Although they state that they did not engage community partners for practical reasons, they recognize that authentic collaborations that involve community participants are essential. They identify key sustainability competencies for students based on three clusters: strategic knowledge, practical knowledge, and collaborative [action]. These clusters overlap qualities identified in the first generation approaches that are described above.

\section{Emergent models}

Emergent models reflect assumptions consistent with dynamically complex systems:

- There are countless, recursively interacting factors that can neither be known nor isolated to simple cause-and-effect relationships;

- Change is the only constant and a multiplicity of valid perspectives co-exist;

- The whole is greater than the sum of its parts ("emergence") and its behavior is not predictable on the basis of the parts.

We analyzed four approaches that we categorized as emergent. These emergent approaches align with a central principle of change strategies, consistent with the recommendations of Henderson, Beach and Finkelstein [30]: the learning process, whether assessment or otherwise, regardless of the level (participant, programmatic, systemic), must be coherent with the nature of the system in which the learning is taking place - in this case, it must be dynamically complex.

With the exception of Garcia et al., [31] these emergent approaches focus on a holistic set of properties or attributes of the system of learning, embrace a system's diversity, and include adaptation as a critical process of learning. Garcia et al. draw from prior models of sustainability 
as a system of learning and focus on assessing faculty learning competencies against six categories of complexity (connections, dialogue, creativity, innovation, critical thinking, uncertainty). Others are more attentive to system attributes. For example, Klein [32] has organized evaluation principles into seven categories: variability of goals; variability of criteria and indicators; leveraging of integration; interactions of social and cognitive factors in collaboration; management, leadership, and coaching; iteration in a comprehensive and transparent system; and effectiveness and impact. Auspos and Cabaj [33] suggest heuristics that include three key functions: strategy and planning; adaptive management; and learning and evaluation. Their suggestions for evaluation include embracing a plurality of valid views, accepting chaos and using legacy assessment approaches (i.e., what we are calling legacy models) only where fit for the purpose. McKnight and Kretzmann's [34] work on Asset-Based Community Development and its more recent derivatives [35] suggests an assessment of community assets. In these emergent cases, the process of assessing the system of learning is both derived and completed through participatory inquiry; the process itself includes learning at a collective level. In a systems approach, individual skills, knowledge and attitudes are not disregarded; they are included in a larger scope of indicators that look at system attributes. These emergent approaches also include attention to the quality of participation across the system.

\section{Discussion}

No consensus on learning evaluation approaches

As indicated in Table 3, there are emerging shared views on the competencies necessary for designing sustainable communities. However, as Klein points out in her review article, "Evaluation of Interdisciplinary and Transdisciplinary Research," the nature of complex research defies a single solution of evaluation [32]. Relevantly, diversity is inherent to complexity. The local milieu conditions the social container of the transdisciplinary setting. By extension, the social container defines the values represented in the evaluation. For example, a community in the greater metropolitan Atlanta area will have their attention on a different set of challenges than a rural community in northern Montana. Nevertheless, we observe an overarching pattern in the emergent practices of evaluating learning in transdisciplinary research: a focus on systemslevel behavior.

It is useful, then, to recall models of systems-level behavior. Although a review of the principles of systems thinking is beyond the scope of this paper, we provide Fig. 1 to illustrate different system perspectives and the action those perspectives enable which was derived from the work of Hall on cultural dynamics [36] and Kim [37]. As the model suggests, the visible systemic events arise from hidden system patterns, themselves arising from a system's structures. Those structures (e.g., physical structures, policies, regulations) are a product of shared mental models ("paradigms") within the system. The mental models result from what might be called "vision" which anticipates a future that embodies values and beliefs. Systems theory suggests that the observable Event, higher in the system, is a result of the cascading effect of the system's deep structures (e.g., shared beliefs \& values, policies and practices), far below the metaphorical tip of the iceberg. 
As an example, a rush-hour traffic jam is an event that arises from the system of traffic. It arises around the work-day pattern of traffic. The pattern is produced from an interaction between the infrastructure of roads and system participants' choices, themselves a product of policies and laws that govern the placement of residential and commercial property. These structures arise from the enculturated mental models of how living and working should be divided. These mental models come from a set of values and beliefs about work, leisure, community, etc. It is true that a traffic jam is ultimately "created" by the individual people, but the jam cannot be found in any one individual. It arises from the collective, dynamic behavior of the system of people, infrastructure, policies, practices, values and beliefs. In the same way, we are suggesting that the learning and designing for sustainability is a systems-level phenomenon that requires perspective and action at the systems level; such learning for sustainability cannot be found by isolated measures of individual learning.

From a systems point of view, the action mode available and its inherent leverage are limited by the level of perspective in a system as depicted in Figure 1. If one only has access to visible events, such as an absence of sustainable communities, they can only be reactive. For adaptive action, one must see the systemic patterns that give rise to what occurs as the problem. Creative action requires a shift in perspective that reveals the systemic structures that give rise to the patterns. As shown in this model, generative action (or transformational-literally transcending the formation of the system) requires a vision of an alternative future that embodies alternative values and beliefs.

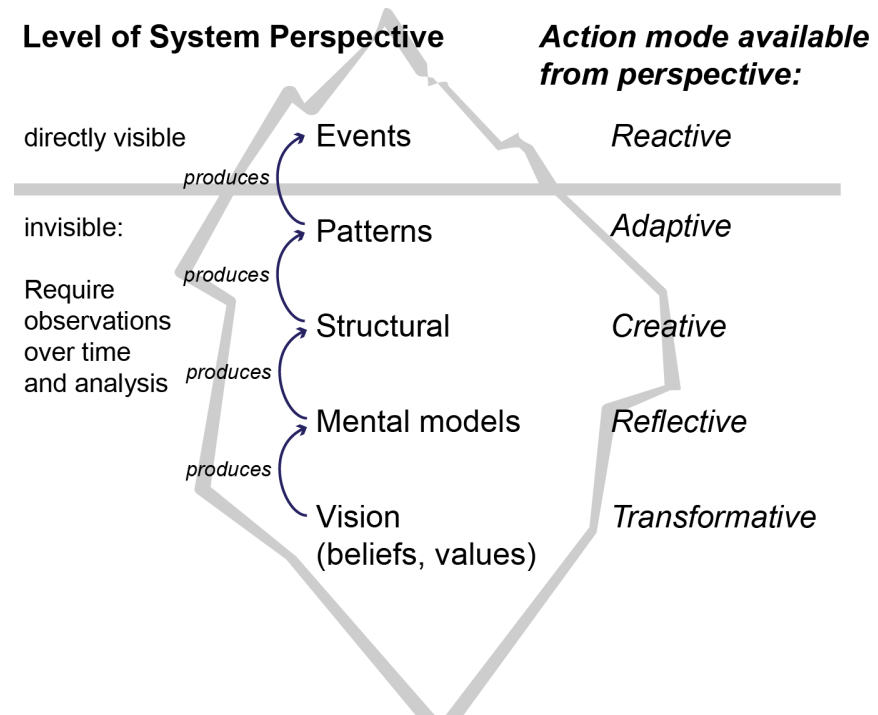

Figure 1. Iceberg model of human systems and intervening action. Adapted from: D.H. Kim [37]; Hall [36].

What this systems model illustrates is that leveraged, systemic transformational action ultimately involves "deeper" cultural interventions. From a systems perspective, if one replaces the system participants and leaves the structures unchanged, the same result will be produced; this may explain things like the disproportionate mass incarceration of African Americans or the persistent bias that disfavors women in science and engineering among academic men and women, reported by a commissioned study of the National Academies in 2006 [38]. Although there have 
been attempts to change outcomes by changing policies, the deeply rooted implicit biases that disadvantage these groups of people function at the belief and values level to keep the dynamics in place. The systems model of Fig. 1 opens a range of systemic learning and subsequent intervention points. We can use this model to develop strategies or experiments to create and sustain complex dynamic systems of learning. In the following section, we offer a unifying framework by which such a strategy could be developed.

\section{A Proposed Unifying Framework}

We suggest that a strategy that is fit for transdisciplinary learning for sustainability should embody three attributes: Holistic, Participatory, and Adaptive ${ }^{4}$. In our model, these three, interpenetrating concepts have like counterparts in the common sustainability frame as shown in Figure 2. As shown, we represent the three sustainability concepts with economy being a subset of society which is a subset of environment. In a similar way, adaptive action lies within participation, which lies within the whole. We describe each of these properties below.

\section{Sustainability Frame}

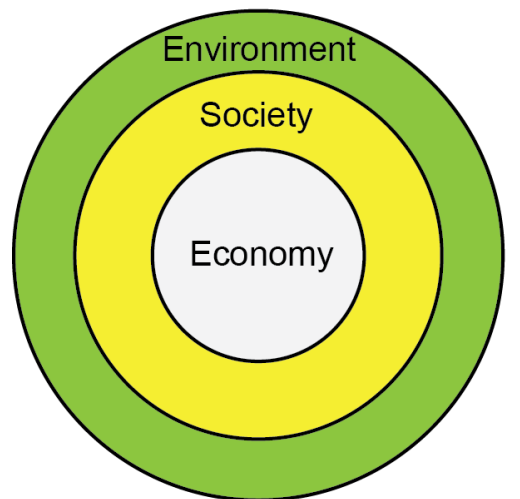

Proposed

Learning System Properties

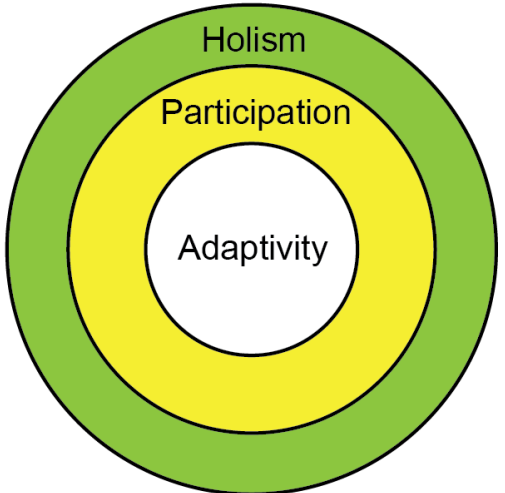

Figure 2. Proposed unifying framework (right) and sustainability frame (left).

\section{$\underline{\text { Holistic }}$}

As reviewed above in Past Approaches, legacy assessment approaches around learning for sustainability have centered on what is considered "student learning," rather than considering the whole system and its dynamics. Traditional metrics applied to student cohorts, such as grade point averages, do not capture transformational changes experienced by participants [16], [39]. A holistic assessment framework would consider a broader attention on holistic development as well as assessing whether learning is happening for all participants and levels of the system: expert, lay, student, staff, faculty, community partners, institutional, community, etc. Examples: broader human development and well-being; systems-level transsector learning; changes in institutional policies and practices; changes in structural/cultural dimensions of the learning environment; qualities of the community-engaged process.

\footnotetext{
${ }^{4}$ Those interested in an extensive explication of community-change efforts around sustainability are directed to Auspos, P. \& Cabaj, M. (2014).
} 
One of the challenges of holism is using a framework that practically encompasses the system's natural diversity (e.g., diversity comes in the form of multiple stakeholders and their interests, contextual details, etc.). Given the impossibility of assessing the infinite dimensions of the whole, which dimensions should be included as a threshold condition? There are several different models that have been used in transdisciplinary sustainability projects. A common protocol for sustainable development identifies indicators that encompass the human, environmental and economic aims of sustainability--we might call this approach equity/environment/economy (e.g., "A framework for strategic sustainable development," [40], "EcoDistricts" [41]). Sustainability pioneer Donella Meadows proposed that a holistic suite of indicators for sustainable development would assess the means and ends of sustainable development: the ultimate ends (well-being), intermediate ends (human and social capital), intermediate means (built capital and human capital) and ultimate means (natural capital) [42]. The work of Auspos and Cabaj [33] suggests a monitoring of complexity-based practices for three key functions: strategy and planning; adaptive management; and learning and evaluation. Whatever the framework that is chosen, a holistic frame requires a systems view that goes beyond individual student learning.

\section{$\underline{\text { Participatory }}$}

A central principle of sustainability is that the (problematic) emergent conditions that threaten the health of critical biological systems that support planetary life are anthropogenic [43]. That is, human actions are causal to the emergence of an unsustainable planetary trajectory. Like a traffic jam, human behavior is the ultimate source. Changes in human behavior are then the means, but these changes must manifest at the collective, systems level. Participation by the affected stakeholders through a democratic process has been shown to be an effective systemslevel change process for complex social issues [7].

The substance of effective participation in transdisciplinary projects is therefore one of shared decision-making across the stakeholder group. This contrasts with a mode of collecting input by "expert" decision-makers that is typical of expert-directed consultation processes [44]. "Citizens, not just technical experts or politicians, have important local knowledge and should have the opportunity to determine their own future as well as how to realize their visions" [45, p. 192]. By engaging system agents in the learning process about systemic change, they themselves become potential change agents. Their behavior becomes a model for others. This type of stakeholder participation recognizes the central role of memes ${ }^{5}$ in propagating cultural change [9]; cultural behavioral changes occur through imitation so engaging participants in the change increases the community of agents of change.

$\underline{\text { Adaptive }}$

A fundamental system property of dynamic complexity is impermanence. The changing nature requires adaptation as typical of situational navigation. This mode of navigating, traditionally used by the Polynesians prior to modern instrumentation to navigate across thousands of miles of open ocean, required close observation of the ever-changing conditions of water, sea life,

\footnotetext{
${ }^{5}$ meme: an element of culture or system behavior that is passed from individual to another through imitation.
} 
weather and sky. They made course adjustments in response to the live conditions. We suggest that navigating transdisciplinarity demands a similar type of real-time observation followed by adaptation.

In an ideal setting, participants in a transdisciplinary project would have immediate feedback on the effects of their actions. They would then adapt through small-scale experimentation and learn from the results [33]. For example, in the theoretical project on water catchment, participants may have a theory that water features with sustainable gardens would lead to greater sense of community and less crime. This theory could be tested with a prototype project and inquiry into changes into the sense of community. The feedback would lead to further adjustments. As suggested by Waddock et al. 's [9], an adaptive evaluation framework would adhere to the heuristics to "prioritize learning in the context of constant change,...work with co-evolution and emergence action framework[s]...[and] emphasize resilience and adaptation" [9, p. 1007].

\section{Reflections on Implications for Research and Next Steps}

There is a compelling reason to initiate local transdisciplinary research projects that goes beyond any desire to move toward a vision of transdisciplinary engineering centers articulated by a commissioned report: the immediate and collective need to transition to a peaceful, sustainable, planetary existence. Entering this learning modality requires a shift to systems of learning. This shift in focus to that of systems properties and behavior is a significant departure from legacy educational approaches that focus solely on student learning outcomes. Legacy models leave other qualities of the system of learning - faculty, environment, culture, structures, historical and social inequities - unexamined. In bringing up these qualities, it is tempting to apply the atomistic scientific models that treat each of these as variables to isolate and manage. However, past learning/research/education practices are based on the science of simple systems where cause-and-effect are knowable and discerned through controlled experimentation. It is our view that the legacy models are a powerful, necessary, but insufficient way of knowing and working toward the goal of learning for sustainability.

We are instead opening a dialogue on the actions of learning/research/education that one would take if we assumed the nature of the learning system is dynamically complex. In doing so, we also acknowledge the gap between our current science and methodologies and what is needed to congruently learn in dynamically complex systems. Although out-of-scope of this paper, such methodologies are emerging "outside" of traditional education in the domains of community change and social change. ${ }^{6}$ A next step in our work is to explore whether the emerging research methodologies that are consistent with dynamically complex systems are helpful in navigating transdisciplinary learning.

\section{Conclusions}

A central question that guided our inquiry was, "Is the substance of a learning system for sustainable design coherent with the conditions required to favor the emergence of systemic,

\footnotetext{
${ }^{6}$ A methodology currently being explored by the authors is that of SenseMaker $\odot$ (http://cognitive-
} edge.com/sensemaker/ ) 
transformational learning?" We suggest that designing learning that leads to sustainable communities is a systems-level phenomenon that requires learning competence with complex, dynamic social systems. The transdisciplinary learning modality is one that has both form and substance as a learning setting coherent with the aims of transformative learning inherent to sustainability. To see into the systems-level learning in transdisciplinarity, we advocate a process of navigating that is holistic, participatory, and adaptive. This process would be derived through participation and grounded in the situational context. The learning process would include holistic assessments across participant groups and at the systems level. This focus on systems-level properties represents a significant departure from current research and learning assumptions and methods. Such a shift in attention to the system of learning requires a new science of complexity. We submit these ideas to open a dialogue on approaches to learning at the systems level.

\section{Acknowledgements}

The authors gratefully acknowledge the reflective feedback on the manuscript provided by Jennifer Hirsch, Director of Serve-Learn-Sustain at Georgia Tech and Lizabeth Schlemer, Associate Dean of Engineering and Professor of Industrial and Manufacturing Engineering, California Polytechnic State University. We also acknowledge the editing contributions of Kelly Ann Fitzpatrick in the preparation of the manuscript. This work was made possible in part by the people of the states of California and Georgia through the employment of the authors. No funding agencies have supported this research.

\section{References}

[1] National Academies of Sciences, Engineering, and Medicine; National Academy of Engineering; Division on Engineering and Physical Sciences; National Materials and Manufacturing Board; and Committee on a Vision for the Future of Center-Based Multidisciplinary Engineering Research. A New Vision for Center-Based Engineering Research. Washington, D.C: The National Academies Press, 2017. http://doi.org/10.17226/24767.

[2] B. Nicolescu, Manifesto of transdisciplinarity. Translated by K-C Voss. SUNY Press, 2002.

[3] J. T. Klein, "A taxonomy of interdisciplinarity," in The Oxford Handbook of Interdisciplinarity, R. Frodeman, J. T. Klein, and C. Mitcham, Eds. Oxford University Press, 2010, pp. 15-30.

[4] D. J. Lang, A. Wiek, M. Bergmann, M. Stauffacher, P. Martens, P. Moll, et al., "Transdisciplinary research in sustainability science: practice, principles, and challenges," Sustainability Science, vol. 7, suppl. 1, pp. 25-43, Feb. 2012. http://doi.org/10.1007/s11625011-0149-x.

[5] T. Jahn, T. Knobloch, W. Krohn, C. Pohl, and E. Schramm, Methods for Transdisciplinary Research: A Primer for Practice. Frankfurt, Germany: Campus Verlag, 2013. 
[6] T. Klein, "Prospects for transdisciplinarity," Futures, vol. 36, no. 4, pp. 515-526, May 2004.

[7] J. Mcintyre-Mills, "Participatory design for democracy and wellbeing: Narrowing the gap between service outcomes and perceived needs" Systemic Practice and Action Research, vo. 23, no. 1, pp. 21-45, Feb. 2010. http://doi.org/10.1007/s11213-009-9145-9.

[8] F.R. Westley, O. Tjornbo, L. Schultz, P. Olsson, C. Folke, B. Crona, and Ö. Bodin, "A theory of transformative agency in linked social-ecological systems," Ecology and Society, vol. 18, no. 3, art. 27, 2013. http://doi.org/10.5751/ES-05072-180327.

[9] S. Waddock, G. M. Meszoely, S. Waddell, and D. Dentoni, "The complexity of wicked problems in large scale change," Journal of Organizational Change Management, vol. 28, no. 6, pp. 993-1012, 2015. http://doi.org/10.1108/JOCM-08-2014-0146.

[10] L. Vanasupa and L. Schlemer, (2014). "Relational versus transactional community engagement: An experience of the benefits and costs," presented at 121st ASEE Annual Conference \& Exposition, Indianapolis, Indiana, 2014. Available: https://peer.asee.org/22970.

[11] C. K. Siemers, B. Harrison, P. H. Clayton, and T. A. Stanley, "Engaging place as partner," Michigan Journal of Community Service Learning, vol. 22, no. 1, pp. 101-104, Fall 2015.

[12] F. D. Beaudoin and K. Brundiers, A Guide for Applied Sustainability Learning Projects: Advancing sustainability outcomes on campus and in the community. Philadelphia: Association for the Advancement of Sustainability in Higher Education (AASHE), 2016.

[13] K. Morton and S. Bergbauer, "A case for community: Starting with relationships and prioritizing community as method in service-learning," Michigan Journal of Community Service Learning, vol. 22, no. 1, pp. 18-31, Fall 2015.

[14] L. Vanasupa, L. Schlemer, R. Burton, C. Brogno, G. Hendrix, and N. MacDougall, "Laying the Foundation for Transdisciplinary Faculty Collaborations: Actions for a Sustainable Future," Sustainability, vol 6, no.5, pp. 2893-2928, 2014. http://doi.org/10.3390/su6052893

[15] J. D. Thompson and B. K. Jesiek, (2017). "Transactional, cooperative, and communal: Relating the structure of engineering engagement programs with the nature of partnerships." Michigan Journal of Community Service Learning, vol. 23, no. 2, pp. 83-99, Spring 2017.

[16] K. Brundiers, A. Wiek, and C. L. Redman, "Real-world learning opportunities in sustainability: from classroom into the real world," International Journal of Sustainability in Higher Education, vol. 11, no. 4, pp. 308-324, 2010. http://doi.org/10.1108/14676371011077540. 
[17] Sustainability Curriculum Consortium. "Peter Buckland \& Elly Engle webinar," YouTube, Oct. 25, 2017 [Video file]. Available: https://youtu.be/J9zk7RdC9U4. [Accessed: Jan. 30, 2018].

[18] M. K. Watson and E. Barrella, E. (2017, June), "A systematic review of sustainability assessments in ASEE proceedings," presented at $124^{\text {th }}$ ASEE Annual Conference \& Exposition, Columbus, Ohio, 2017. Available: https://peer.asee.org/27525.

[19] M. K. Watson, J. Pelkey, M. O. Rodgers, \& C. R. Noyes, "Exploring student sustainability knowledge using the Structure of Observed Learning Outcomes (SOLO) Taxonomy," presented at $121^{\text {st }}$ ASEE Annual Conference \& Exposition, Indianapolis, Indiana, 2014. Available: https://peer.asee.org/20474.

[20] S. Hoffmann, A. L. Pawley, and A. Pawley, (2011). "Defining 'sustainable engineering': A comparative analysis of published sustainability principles and existing courses," presented at 118th ASEE Annual Conference \& Exposition, June 2011. Available: https://peer.asee.org/17699

[21] M. Svanström, F. J. Lozano García, and D. Rowe, "Learning outcomes for sustainable development in higher education," International Journal of Sustainability in Higher Education, vol. 9, no. 3, pp. 339-351, 2008. http://doi.org/10.1108/14676370810885925.

[22] S. Santone, Integrating Sustainability Across the Curriculum. Ypsilanti, MI: Creative Change Educational Solutions, 2014.

[23] A. Wiek, L. Withycombe, C. Redman, and S. Banas Mills, S. (2011) "Moving forward on competence in sustainability research and problem solving," Environment: Science and Policy for Sustainable Development, vol. 53, no. 2, pp. 3-13, 2011. https://doi.org/10.1080/00139157.2011.554496.

[24] L. W. Anderson, D. R. Krathwohl, P. Airasian,, K. Cruikshank, R. Mayer, P. Pintrich, and M. Wittrock, A Taxonomy for Learning, Teaching and Assessing: A revision of Bloom's taxonomy. New York. Longman Publishing, 2001.

[25] P. M. King, "William Perry's theory of intellectual and ethical development," New Directions for Student Services, vol. 1978, no. 4, pp. 35-51. doi:10.1002/ss.37119780405.

[26] P. M. King and K. S. Kitchener, Developing Reflective Judgment: Understanding and Promoting Intellectual Growth and Critical Thinking in Adolescents and Adults. Jossey-Bass Higher and Adult Education Series and Jossey-Bass Social and Behavioral Science Series. San Francisco: Jossey-Bass, 1994.

[27] A. S. Van Epps, I. Ashby, C. M. Gray, and M. Exter, "Supporting student attainment and management of competencies in a transdisciplinary degree program," presented at $123^{\text {rd }}$ ASEE Annual Conference \& Exposition, New Orleans, Louisiana, 2016. doi:10.18260/p.25977. 
[28] H. Glasser and J. Hirsh, "Toward the development of robust learning for sustainability core competencies," Sustainability: The Journal of Record, vol. 9, no. 3, pp. 121-134, Sep 2016.

[29] W. E. Engels, S. H. Barson, L. Vandenbergh, G. E. Sterner, and R. A. Theodore, "Developing a framework for sustainability meta-competencies," 2017. In Press.

[30] C. Henderson, A. Beach, and N. Finkelstein, "Facilitating change in undergraduate STEM instructional practices: An analytic review of the literature," Journal of Research in Science Teaching, vol. 48, pp. 952-984, 2011. doi:10.1002/tea.20439.

[31] Garcia, M. R., M. Junyet and M. Fonolleda, "How to assess professional competencies in Education for Sustainability? An approach from a perspective of complexity." Journal of Sustainability in Higher Education, vol. 18, no. 5, pp. 772-797, 2017. http://doi.org/10.1108/IJSHE-03-2016-0055.

[32] J. T. Klein, (2008). "Evaluation of interdisciplinary and transdisciplinary research," American Journal of Preventive Medicine, vol. 35, no. 2, pp. S116-S123, 2008. http://doi.org/10.1016/j.amepre.2008.05.010

[33] P. Auspos and M. Cabaj, Complexity and Community Change: Roundtable on Community Change. Washington, D.C.: The Aspen Institute, 2014.

[34] J. McKnight and J. Kretzmann, Building Communities from the Inside Out: A Path Toward Finding and Mobilizing a Community's Assets. Chicago, IL: ACTA Publications, 1993.

[35] A. Haines, "Asset-based community development." in An Introduction to Community Development, R. Phillips and R. Pittman, Eds. UK: Routledge, 2009, pp. 38-48.

[36] E. T. Hall, Beyond Culture. Anchor, 1976.

[37] D. H. Kim, "Introduction to systems thinking," IMS0013E, Pegasus Communications, Inc., 1999. Available: https://thesystemsthinker.com/introduction-to-systems-thinking/.

[38] Committee on Maximizing the Potential of Women in Academic Science and Engineering, National Academy of Engineering (2006). Beyond Bias and Barriers: Fulfilling the Potential of Women in Academic Science and Engineering. National Academies Press, 2006. Available: http://books.nap.edu/catalog/11741.html.

[39] L. Schlemer, K. Hensley, R. Pittman, J. Golland, P. Hatcher, and E. Candelaria, (2015). "SUSTAIN SLO: Reenergizing learning" Proceeding of $122^{\text {nd }}$ ASEE Annual Conference, Seattle, WA, 2015. Available: https://peer.asee.org/24785.

[40] G. I. Broman and K. H. Robèrt, "A framework for strategic sustainable development," Journal of Cleaner Production, vol. 140, pp. 17-31, 2017. 
[41] C. Agbannawag, "EcoDistricts: Bridging the gap between plans and projects," University of Arizona Open Repository, 2015. Available:

http://arizona.openrepository.com/arizona/handle/10150/553052.

[42] D. Meadows, Indicators and Information systems for Sustainable Development: A Report to the Balaton Group. Hartland, VT: The Sustainability Institute, 1998, pp. 1-95.

[43] P. J. Crutzen and W. Steffen, "How long have we been in the Anthropocene era?" Climatic Change, vol. 61, no. 3, pp. 251-257, 2003.

[44] M. Mobjork, "Consulting versus participatory transdisciplinarity: A refined classification of transdisciplinary research," Futures, vol. 42, no. 8, pp. 866-873, 2010.

http://doi.org/10.1016/j.futures.2010.03.003

[45] M. Zint and K. Wolske, (2014). "From information provision to participatory deliberation: Engaging residents in the transition toward sustainable cities," in D. Mazmanian, and H. Blanco, Eds. The Elgar Companion to Sustainable Cities: Strategies, Methods and Outlook. Northampton, MA: Edward Elgar Publishing, 2014, pp. 188-209. 